\title{
Preferential association between childhood emotional abuse and bipolar disorder
}

\begin{tabular}{|c|c|}
\hline Journal: & Journal of Traumatic Stress \\
\hline Manuscript ID: & JOTS-08-0280.R4 \\
\hline Wiley - Manuscript type: & Research Article \\
\hline $\begin{array}{r}\text { Date Submitted by the } \\
\text { Author: }\end{array}$ & 29-Jan-2010 \\
\hline Complete List of Authors: & $\begin{array}{l}\text { Etain, Bruno; Hopital Albert Chenevier, Pole de Psychiatrie } \\
\text { Mathieu, Flavie } \\
\text { Henry, Chantal } \\
\text { Raust, Aurelie } \\
\text { Roy, Isabelle } \\
\text { Germain, Anne } \\
\text { Leboyer, Marion } \\
\text { Bellivier, Frank }\end{array}$ \\
\hline Keyword - Topics: & Etiology/risk and protective factors \\
\hline $\begin{array}{r}\text { Keywords - Trauma } \\
\text { Exposure: }\end{array}$ & Sexual abuse/assault, childhood \\
\hline $\begin{array}{r}\text { Keyword - Statistical } \\
\text { Categories: }\end{array}$ & \\
\hline \multicolumn{2}{|l|}{ Keyword - Intervention: } \\
\hline $\begin{array}{r}\text { Keyword - Special } \\
\text { Populations: }\end{array}$ & \\
\hline
\end{tabular}

\section{(s) ScholarONE" \\ Manuscript Central}


Preferential association between childhood emotional abuse and bipolar disorder

Running head: Emotional abuse and bipolar disorder

Bruno ETAIN (1,3), Flavie MATHIEU (1), Chantal HENRY (1,2,3), Aurélie RAUST (1,3), Isabelle ROY (3), Anne GERMAIN (4), Marion LEBOYER (1,2,3), Frank BELLIVIER (1,2,3).

1) INSERM, Unité 955, IMRB, Pôle de Génomique Médicale, Equipe de Psychiatrie Génétique, Créteil, F-94000, France ;

2) Université Paris Est, Faculté de Médecine, IFR10, Créteil, F-94000, France ;

3) AP-HP, Groupe Henri Mondor-Albert Chenevier, Pôle de Psychiatrie, Créteil, F-94000,

France ;

4) Department of Psychiatry, University of Pittsburgh School of Medicine, Pennsylvania, USA. 
Corresponding author:

Bruno ETAIN, MD, PhD.

Pôle de Psychiatrie

Hôpital Albert Chenevier

40, rue de Mesly

94010 Créteil Cedex - FRANCE

Tel: + 33149813290

Fax: + 33149813099

Mail : bruno.etain@inserm.fr

Conflict of interest: none

Word count: 111 (abstract); 5937 (article with references, tables and figures); 4 tables; 1 figure

\begin{abstract}
Acknowledgements
This work was supported by INSERM, Assistance Publique des Hôpitaux de Paris (AP-HP), Agence Nationale pour la Recherche (ANR - Project Manage-BP), Fondation pour la Recherche sur le Cerveau (FRC) and RTRS Santé Mentale (Fondation FondaMental). We thank E. Abadie, C. Bulach, B. Cochet, M. Fabbro and M.J. Pereira Gomes for their assistance. We thank patients and controls for their participation.
\end{abstract}


Abstract

Key words:

Bipolar disorder, childhood affective trauma, childhood trauma questionnaire, emotional abuse, dose-effect. 
Introduction

Bipolar affective disorder is a chronic and severe psychiatric disorder of multifactorial origin. More than 20 years after the demonstration of its genetic component, the search for susceptibility genes is still inconclusive (Smoller \& Gardner-Schuster, 2007). This may be partly explained by the under-exploration of the environmental aspects of the disease that require to be incorporated in the analysis. Psychological stressors are probably the most promising environmental determinants (Etain, Henry, Bellivier, Mathieu, \& Leboyer, 2008) and have been implicated in the onset and recurrences of unipolar and bipolar affective disorders (Cohen, Hammen, Henry, \& Daley, 2004; Paykel, 2003; Post, 1992). Most investigations have focused on recent major life events, implicating both acute and chronic stressors while the role of early childhood trauma remains under-explored (Johnson \& Roberts, 1995; Paykel, 2003; Rush, 2003).

Childhood traumatic events are more frequently reported by bipolar than by unipolar patients (Hyun, Friedman, \& Dunner, 2000). Histories of severe childhood abuse were identified in more than half of the bipolar patients (Garno, Goldberg, Ramirez, \& Ritzler, 2005; Maguire, McCusker, Meenagh, Mulholland, \& Shannon, 2008). Childhood traumatic events may also modulate the clinical expression of the disorder, being associated with an earlier onset of the disease (Garno et al., 2005), rapid cycling course (Garno et al., 2005; Leverich \& Post, 2006), psychotic features (Hammersley et al., 2003), suicidal behavior (Brown, McBride, Bauer, \& Williford, 2005; Garno et al., 2005; Leverich \& Post, 2006), comorbidities with substances misuse (Brown et al., 2005; Garno et al., 2005; Leverich \& Post, 2006) and with panic disorder (Brown et al., 2005). These data thus suggest that childhood trauma may be an associated risk in 
bipolar disorder and may also influence its clinical expression and outcome (Etain et al., 2008).

However, many studies in this field have been hampered by methodological limitations, particularly the absence of control groups, but also differences between assessment methods (structured interview versus self-reported measure) and small samples of patients. The preferential implication of some subtypes of trauma also requires further investigation since most studies have considered childhood trauma as a whole or have restricted the investigation to physical and/or sexual abuses (Carballo et al., 2008; Hammersley et al., 2003). Since interaction between a given subtype of trauma with specific genetic factors might be the causal link to a given psychiatric condition (Caspi \& Moffitt, 2006), the association between bipolar disorder and different subtypes of trauma requires to be formally tested. Finally, a dose-effect of trauma subtypes has never been investigated in bipolar disorder although this effect has previously been reported in other psychopathological conditions, such as in psychosis (Read, van Os, Morrison, \& Ross, 2005).

The aims of this study were thus (i) to retrospectively assess the prevalence and the severity of different subtypes of childhood trauma among euthymic bipolar patients and controls, (ii) to investigate the preferential implication of some trauma subtypes and (iii) to test for their dose-effect.

Method

Participants 
Bipolar type I and type II patients (according to DSM-IV criteria (American Psychiatric Association, 1994)) were recruited in two university-affiliated psychiatric departments in France (Paris/Créteil and Bordeaux). Inclusion criteria for bipolar patients were age over 18 years, caucasian and normothymia defined as a Montgomery Asberg Depression Rating Scale and a Mania Rating Scale scores below five (Bech, Rafaelsen, Kramp, \& Bolwig, 1978; Montgomery \& Asberg, 1979). The control group was composed of blood donors having neither a personal nor a familial (first-degree relatives) history of mood disorders or suicidal behavior .

\section{Measures}

All participants were interviewed using the French version (Preisig, Fenton, Matthey, Berney, \& Ferrero, 1999) of the Diagnostic Interview for Genetic Studies (DIGS) (Nurnberger et al., 1994) providing lifetime DSM-IV axis I diagnoses (American Psychiatric Association, 1994). To check the inter-rater reliability for DSM-IV axis I diagnoses, the following procedure was applied (Preisig et al., 1999). A team of interviewers (8 psychologists and psychiatrists) was trained over a four month period using videotaped interviews and supervisions with experienced clinicians. All interviewers were blinded as to the referral diagnosis of the subject. Raters performed interviews for the inter-rater and test-retest reliability study in a balanced way, exchanging roles between first-interviewer, observer at the first interview, and retest interviewer. Patients were interviewed by a member of the team in the presence of an observer (co-rater) who simultaneously and independently completed a DIGS. At the end of the interview, interviewer and observer independently assigned DSM-IV lifetime diagnoses. The inter-rater reliability was computed on 136 patients from psychiatric inpatient and outpatient facilities with referral diagnoses of bipolar disorder, major depressive disorder, schizoaffective disorder, 
schizophrenia/schizophreniform disorder, alcohol or drug disorder. The inter-rater reliabilities (kappa coefficients) we achieved for the DIGS were 0.85 for bipolar disorders (Preisig et al., 1999) and 0.93 for major depressive disorder/dysthymia, this being consistent with the inter-rater reliabilities of the English version (Nurnberger et al., 1994). The French version of the DIGS has no specific section to check the presence of posttraumatic stress disorder.

Childhood traumatic events were recorded using the short version of the Childhood Trauma Questionnaire (CTQ), a 28-item self-report measure developed by Bernstein et al. (Bernstein et al., 1994). This questionnaire showed excellent test-retest reliability, as well as convergent and discriminant validity with a structured trauma interview. It has been validated in clinical and non clinical populations (Bernstein \& Fink, 1998). The CTQ yields a total score (range 25-125) that is recommended to be used as a continuous variable, and five sub-scores (range 5-25 for each) for neglects (emotional and physical) and abuses (emotional, physical and sexual) (recommended to be used as categorical variables). Emotional neglect refers to the failure of caretakers to provide basic psychological and emotional needs, such as love, encouragement, belonging and support. Emotional abuse refers to verbal assaults on a child's sense of worth or well-being, or any humiliating, demeaning, or threatening behavior directed toward a child by an older person. Physical neglect refers to failure to provide basic physical needs including food, shelter, and safety.

Physical abuse refers to bodily assaults on a child by an older person that pose a risk of, or result in, injury. Sexual abuse refers to sexual contact or conduct between a child and an older person, including explicit coercion. 
According to the thresholds provided by Bernstein et al. (1994), each subtype of trauma was categorized across a gradient of four levels of severity, from "no trauma" to "severe" through low and moderate. In this study, a trauma subtype was considered as present if reaching at least a low level of severity. The French validated version of the CTQ was used in this study (Paquette, Laporte, Bigras, \& Zoccolillo, 2004). Bipolar patients' euthymic state was checked using the French versions of the Montgomery Asberg Depression Rating Scale and of the Mania Rating Scale (Bech et al., 1978; Montgomery \& Asberg, 1979) before the CTQ completion.

Procedure

For this study, participants who fulfilled inclusion criteria were systematically approached (about 250 bipolar patients and 100 control subjects). More than $80 \%$ of approached participants did agree to participate and all of them have then been included in the study. Comparisons between participants and non-participants were not available since French ethical procedures do not allow collecting the characteristics of non participants.

For bipolar patients, normothymia was assessed using the Montgomery Asberg Depression Rating Scale and the Mania Rating Scale with scores requiring to be below five (Bech, Rafaelsen, Kramp, \& Bolwig, 1978; Montgomery \& Asberg, 1979). Then, the DIGS was completed in order to characterize bipolar disorders and psychiatric comorbidities. Controls were screened for DSM-IV axis I diagnoses using the DIGS and included in this study only if they met the inclusion criteria. They completed the CTQ only if they were free of personal and familial (first-degree relatives) history of mood disorders (major depressive episodes or unipolar disorder) or suicidal behavior and had a Montgomery Asberg Depression Rating Scale and the Mania 
Rating Scale scores below five (Bech, Rafaelsen, Kramp, \& Bolwig, 1978; Montgomery \& Asberg, 1979).

For all participants, CTQ was completed after the completion of the DIGS. About $5 \%$ of the questionnaires were not included in the analysis since they were not correctly completed (missing items).

Written informed consent was obtained from all participants. Institutional review board approval was previously obtained for this study.

Data analysis

CTQ total score was used as a continuous variable representing the global severity of childhood trauma. Shapiro-Wilk tests were used to test whether the CTQ total scores fitted normal distributions in each group. If scores were not normally distributed, non-parametric tests were used and results were reported using the normal approximation of the statistic $(z)$. Exact pvalues were estimated by simulation over 100.000 replicates. All trauma subtypes were categorized using four levels of severity ("no trauma", "low", "moderate" and "severe") as defined by Berstein et al. (Bernstein \& Fink, 1998). The significance of differences between groups was assessed using classical chi-squared tests for discrete variables. Spearman correlations were used to estimate correlation between trauma subtypes. Logistic regression (simple and multiple), crude and adjusted odds-ratio (OR) and 95\% Confidence Interval (95\% CI) were used to test for an association between bipolar/control status and each trauma subtype. The best model was selected using a classical likelihood ratio test or Akaike criterion. Cochran- 


\begin{abstract}
Armitage linearity test was used to test for an association between trauma subtypes and bipolar disorder. Statistical analyses were performed using the SAS package (version 9.1.2, SAS Institute $\left.{ }^{\circledR}\right)$. Bonferroni's correction was used to allow for multiple testing. Given the number of tests, a p-value equal or lower than 0.003 was considered as significant.
\end{abstract}

Results

The CTQ was completed by 206 bipolar patients (155 bipolar type I and 51 bipolar type II) and by 94 control subjects. Age at interview was similar in the two groups $(M=41.7, S D=$ 12.6 years for bipolar patients and $M=41.2, S D=11.9$ years for control subjects, $z=-0.05, n s$ ). The sex ratio (men/women) was significantly lower in the bipolar patient group than in the control group $\left(0.69\right.$ versus $\left.1.61, \chi^{2}(1, N=300)=11.3, p=.0008\right)$. The characteristics of the samples are detailed in table 1.

The CTQ total score for both bipolar patients and control subjects groups did not fit normal distributions (Shapiro-Wilk test $p<.0001$ for the two groups). Consequently, non parametric tests were used to test for differences between bipolar patients and control subjects. Age at interview and gender had no effect on CTQ total score in the two groups (data available on request).

The CTQ total score was significantly higher for bipolar patients than for control subjects (respectively $M=43.4, S D=13.5$ and $M=36.3, S D=7.4 ; z=-5.02, p<.0001$ ). 
No category of trauma was more frequent for women than for men in either group, except a trend for sexual abuse in the bipolar sample (presence in $37.7 \%$ of women versus $24.4 \%$ of men $\left.\chi^{2}(1, n=206)=6.15, p=.01\right)$. Therefore, analyses were not stratified by gender.

The prevalence of each subtype of trauma are given for bipolar patients and controls in table 2. Frequency distributions between bipolar patients and controls were significantly different only for emotional abuse, but not for emotional neglect, physical neglect, physical abuse or sexual abuse.

The presence of multiple trauma (at least 2 subtypes of at least a low intensity) was significantly more frequent in bipolar patients than in controls $\left(63.09 \%\right.$ versus $32.98 \% ; \chi^{2}(1, N=$ $300)=23.56, p<.0001 ; \mathrm{OR}=3.48,95 \% \mathrm{CI}=2.08-5.82)$. The higher the cumulative number of trauma was, the higher the proportion of bipolar patient in a category (Cochrane-Armitage linear tendency test $z=-4.52, p<.0001)$.

The five subtypes of trauma were correlated as presented in table 3. Simple logistic regression was performed including the five subtypes of trauma independently; then multiple regression was used including the five subtypes of trauma (full model). Logistic regression analysis results are presented in table 4 . The best model includes only emotional abuse as an explanatory variable. Likelihood ratio test of the full model versus emotional abuse only was $\operatorname{similar}\left(\chi^{2}(4, N=300)=6.4, n s\right)$. Emotional abuse was associated with bipolar status when considering the most parsimonious model $(p<.0001)$. 
Finally, the Cochran-Armitage linear trend showed that the higher the emotional abuse severity was, the higher the proportion of bipolar patients in the group across the gradient of severity, as shown in figure 1.

Discussion

Euthymic adult bipolar patients experienced more severe and more frequent childhood traumatic events than control subjects. More than half of our bipolar sample reported childhood trauma, this being consistent with several previous studies (Garno et al., 2005; Leverich et al., 2002; Maguire et al., 2008). This study is the first to investigate five trauma subtypes frequency and severity in a case-control design, and to test for their preferential implication and dose-effect. The association between childhood trauma and bipolar disorder is mainly due to the overrepresentation of emotional abuse in patients with a dose-effect relationship. This is consistent with previous studies showing a dose-effect association between childhood trauma severity and various psychiatric disorders during adulthood (for review see (Read et al., 2005)). Our results thus suggest that, among trauma subtypes, emotional abuse may be preferentially associated with bipolar disorder.

This study has several strengths: the comparison with a control group that has been screened for personal and first-degree relatives history of psychiatric disorders and the use of a reliable, validated trauma questionnaire that provides information about trauma frequency and severity and allows fine-grained analysis for trauma subtypes and dose-effect. Nevertheless, this study design also has several limitations. 
First, the retrospective assessment of traumatic events during childhood may be influenced by uncontrolled recall bias although reports on trauma by psychiatric patients were suggested as remarkably reliable (Meyer, Muenzenmaier, Cancienne, \& Struening, 1996). A recall bias in trauma assessment due to time elapsed since exposure is unlikely in our study (no correlation between CTQ total score and age at interview in both groups, no correlation between CTQ total score and duration of illness or the number of major episodes among bipolar patients; data not shown). Furthermore, the CTQ is a reliable, valid trauma questionnaire and its psychometric properties have shown high levels of face validity, internal consistency, test-retest validity and good convergent validity with structured interviews (Bernstein \& Fink, 1998; Bernstein et al., 1994; Bernstein et al., 2003; Paivio \& Cramer, 2004). Nevertheless and ideally, external sources of information should have been used to check validity.

In this study, the history of trauma was assessed during euthymic states in order to avoid recall bias due to current mood symptoms that may lead to under or over report traumatic experiences. Nevertheless, the potential influence of residual symptoms cannot be completely ruled out. Finally, groups were not matched for gender and this may have influenced the findings, although no effect of gender on the CTQ total score was observed.

The high prevalence and the severity of childhood emotional abuse in our sample could be interpreted in several ways, nevertheless with caution. Emotional abuse might be regarded as a potential risk factor for developing bipolar disorder. Indeed, childhood trauma might show longlasting effects on catecholamine response to psychological stress (Otte et al., 2005; Roy, 2002), on corticotropin-releasing factor systems hyper-reactivity (Heim \& Nemeroff, 2001; Heim et al., 
2002) and might alter function and structure of medial prefrontal cortex and hippocampus (Bremner, 2002). All these neurobiological changes might lead to inadequate emotional regulation (Kooiman et al., 2004; Nemeroff, 2004), thus favoring the emergence of the disorder, for example by revealing a pre-existing genetic susceptibility or by interacting with other environmental stressors (Caspi \& Moffitt, 2006).

The elevated CTQ score observed among bipolar patients may also be regarded as a consequence of behavioral disturbances associated either with an early onset of the disease, with prodromal features (existing before the adulthood onset of bipolar disorder) or with early onset comorbid disorders. For example, early onset bipolar disorder has been associated with conduct disorder, disruptive behavior disorders (Biederman et al., 2000; Spencer et al., 2001), attention deficit with hyperactivity (Kent \& Craddock, 2003) and substance abuse comorbidity (Lin et al., 2006). These clinical features might induce dysfunctional parental attitudes and this burden is likely to lead to inappropriate discipline and in certain conditions to abuse. Furthermore, caregivers of bipolar patients exhibit high levels of expressed emotion, including critical, hostile, or over-involved attitudes (Heru \& Ryan, 2004; Ogilvie, Morant, \& Goodwin, 2005; Perlick et al., 1999; Romero, Delbello, Soutullo, Stanford, \& Strakowski, 2005). Finally, the association between emotional abuse and bipolar disorder might be related to parental psychopathological traits. Indeed, epidemiological studies have shown that affective disorders and alcoholism are more prevalent among relatives of bipolar children than other children (Smoller \& Finn, 2003; Todd, Geller, Neuman, Fox, \& Hickok, 1996). This high prevalence might result in less cohesive and organized, and more conflictual families (Chang, Blasey, Ketter, \& Steiner, 2001; Romero et al., 2005), in turn resulting in an increased likelihood of traumatic events during childhood. 
Childhood trauma, in particular emotional abuse, has also been reported in recurrent unipolar depression (Bernet \& Stein, 1999; Moskvina et al., 2007), thus our results are probably not specific to bipolar disorder. This potentially shared environmental factor has been supposed to be associated with heightened emotional stress reactivity (Glaser, van Os, Portegijs, \& MyinGermeys, 2006), that might be a common feature between bipolar disorder and unipolar recurrent depression (Hlastala et al., 2000; Myin-Germeys et al., 2003). Our findings may shed some light on common psychopathological dimensions in unipolar and bipolar disorders in relation with shared early environmental stressors. This remains speculative and should be formally tested in samples including both bipolar and unipolar patients.

If confirmed, the preferential association between childhood emotional abuse and bipolar affective disorder during adulthood may have several clinical implications. First, histories of childhood trauma required to be routinely assessed in clinical practice among bipolar patients. Unless trauma histories are systematically assessed, they are unlikely to come to the attention of treatment professionals (Bernstein \& Fink, 1998). A systematic assessment may dramatically improve the detection of such traumatic events.

The potential therapeutic implications are of major importance (Celano \& Rothbaum, 2002; Putnam \& Hulsmann, 2002). First, trauma-focused psychotherapies, using different theoretical models, have been suggested to produce clinical benefits in different subgroups of patients with history of childhood abuse (Azar \& Weinzierl, 2005; Callahan, Price, \& Hilsenroth, 2004; Celano \& Rothbaum, 2002; Mueser et al., 2007; Price, Hilsenroth, Petretic-Jackson, \& Bonge, 2001; Wheeler, 2007). To date, no substantial evidence exists that such treatment modalities are effective in bipolar patients with prior abuse and further researches are required in 


\begin{abstract}
this field. Since childhood trauma are supposed to increase stress sensitivity and reactivity (Glaser et al., 2006; Heim et al., 2000; Shack, Averill, Kopecky, Krajewski, \& Gummattira, 2004), we may postulate that some psychotherapeutic approaches might target these potential late consequences of early trauma. This is of great interest since stress reactivity was supposed to be associated with a greater proneness toward relapses (Hlastala et al., 2000; Myin-Germeys et al., 2003; Post \& Leverich, 2006). However, such hypothesis requires further investigation.
\end{abstract}

Conclusion

Bipolar patients reported more frequent and more severe forms of childhood trauma than controls. This result suggests that childhood trauma might represent a risk factor to bipolar disorder, although without definitively demonstrated causality. These findings involve that clinicians should be aware of such environmental risk factors and routinely evaluate histories of childhood trauma among bipolar patients. This potentially leads to trauma-focused therapeutic interventions in patients with such past history. We report for the first time a preferential implication and a dose-effect of childhood emotional abuse in bipolar patients, which may represent either a specific risk factor or a characteristic correlated with other risk factors in offspring such as familial/genetic susceptibility factors or parental psychopathology. Further case-control studies and high risk studies are required to replicate these findings and to investigate the preferential implication of emotional abuse in bipolar disorder. 


\title{
References
}

\author{
American Psychiatric Association. (1994). Diagnostic and Statistical Manual of Mental \\ Disorders, Fourth Edition. Washington DC.
}

Azar, S. T., \& Weinzierl, K. M. (2005). Child maltreatment and childhood injury research: a cognitive behavioral approach. Journal of Pediatric Psychology, 30, 598-614.

Bech, P., Rafaelsen, O. J., Kramp, P., \& Bolwig, T. G. (1978). The mania rating scale: scale construction and inter-observer agreement. Neuropharmacology, 17, 430-431.

Bernet, C. Z., \& Stein, M. B. (1999). Relationship of childhood maltreatment to the onset and course of major depression in adulthood. Depression and Anxiety, 9, 169-174.

Bernstein, D. P., \& Fink, L. (1998). Childhood Trauma Questionnaire : a retrospective selfreport - Manual. San Antonio: The psychological Corporation - Harcourt Brace and Company. Bernstein, D. P., Fink, L., Handelsman, L., Foote, J., Lovejoy, M., Wenzel, K., et al. (1994). Initial reliability and validity of a new retrospective measure of child abuse and neglect. American Journal of Psychiatry, 151, 1132-1136.

Bernstein, D. P., Stein, J. A., Newcomb, M. D., Walker, E., Pogge, D., Ahluvalia, T., et al. (2003). Development and validation of a brief screening version of the Childhood Trauma Questionnaire. Child Abuse \& Neglect, 27, 169-190.

Biederman, J., Mick, E., Faraone, S. V., Spencer, T., Wilens, T. E., \& Wozniak, J. (2000). Pediatric mania: a developmental subtype of bipolar disorder ? Biological Psychiatry, 48, 458466.

Bremner, J. D. (2002). Neuroimaging of childhood trauma. Seminars in Clinical Neuropsychiatry, 7, 104-112.

Brown, G. R., McBride, L., Bauer, M. S., \& Williford, W. O. (2005). Impact of childhood abuse 
on the course of bipolar disorder: a replication study in U.S. veterans. Journal of Affective Disorders, 89, 57-67.

Callahan, K. L., Price, J. L., \& Hilsenroth, M. J. (2004). A review of interpersonalpsychodynamic group psychotherapy outcomes for adult survivors of childhood sexual abuse. International Journal of Group Psychotherapy, 54, 491-519.

Carballo, J. J., Harkavy-Friedman, J., Burke, A. K., Sher, L., Baca-Garcia, E., Sullivan, G. M., et al. (2008). Family history of suicidal behavior and early traumatic experiences: additive effect on suicidality and course of bipolar illness ? Journal of Affective Disorders, 109, 57-63.

Caspi, A., \& Moffitt, T. E. (2006). Gene-environment interactions in psychiatry: joining forces with neuroscience. Nature Reviews Neuroscience, 7, 583-590.

Celano, M., \& Rothbaum, B. O. (2002). Psychotherapeutic approaches with survivors of childhood trauma. Seminars in Clinical Neuropsychiatry, 7, 120-128.

Chang, K. D., Blasey, C., Ketter, T. A., \& Steiner, H. (2001). Family environment of children and adolescents with bipolar parents. Bipolar Disorders, 3, 73-78.

Cohen, A. N., Hammen, C., Henry, R. M., \& Daley, S. E. (2004). Effects of stress and social support on recurrence in bipolar disorder. Journal of Affective Disorders, 82, 143-147.

Etain, B., Henry, C., Bellivier, F., Mathieu, F., \& Leboyer, M. (2008). Beyond Genetics: Childhood Affective Trauma in Bipolar Disorder. Bipolar Disorders, 10, 867-876.

Garno, J. L., Goldberg, J. F., Ramirez, P. M., \& Ritzler, B. A. (2005). Impact of childhood abuse on the clinical course of bipolar disorder. British Journal of Psychiatry, 186, 121-125.

Glaser, J. P., van Os, J., Portegijs, P. J., \& Myin-Germeys, I. (2006). Childhood trauma and emotional reactivity to daily life stress in adult frequent attenders of general practitioners. Journal of Psychosomatic Research, 61, 229-236.

Hammersley, P., Dias, A., Todd, G., Bowen-Jones, K., Reilly, B., \& Bentall, R. P. (2003). 
Childhood trauma and hallucinations in bipolar affective disorder: preliminary investigation. British Journal of Psychiatry, 182, 543-547.

Heim, C., \& Nemeroff, C. B. (2001). The role of childhood trauma in the neurobiology of mood and anxiety disorders: preclinical and clinical studies. Biological Psychiatry, 49, 1023-1039.

Heim, C., Newport, D. J., Heit, S., Graham, Y. P., Wilcox, M., Bonsall, R., et al. (2000).

Pituitary-adrenal and autonomic responses to stress in women after sexual and physical abuse in childhood. JAMA : the Journal of the American Medical Association, 284, 592-597.

Heim, C., Newport, D. J., Wagner, D., Wilcox, M. M., Miller, A. H., \& Nemeroff, C. B. (2002).

The role of early adverse experience and adulthood stress in the prediction of neuroendocrine stress reactivity in women: a multiple regression analysis. Depression and Anxiety, 15, 117-125. Heru, A. M., \& Ryan, C. E. (2004). Burden, reward and family functioning of caregivers for relatives with mood disorders: 1-year follow-up. Journal of Affective Disorders, 83, 221-225.

Hlastala, S. A., Frank, E., Kowalski, J., Sherrill, J. T., Tu, X. M., Anderson, B., et al. (2000). Stressful life events, bipolar disorder, and the "kindling model". Journal of Abnormal Psychology, 109, 777-786.

Hyun, M., Friedman, S. D., \& Dunner, D. L. (2000). Relationship of childhood physical and sexual abuse to adult bipolar disorder. Bipolar Disorders, 2, 131-135.

Johnson, S. L., \& Roberts, J. E. (1995). Life events and bipolar disorder: implications from biological theories. Psychological Bulletin, 117, 434-449.

Kent, L., \& Craddock, N. (2003). Is there a relationship between attention deficit hyperactivity disorder and bipolar disorder? Journal of Affective Disorders, 73, 211-221.

Kooiman, C. G., van Rees Vellinga, S., Spinhoven, P., Draijer, N., Trijsburg, R. W., \& Rooijmans, H. G. (2004). Childhood adversities as risk factors for alexithymia and other aspects of affect dysregulation in adulthood. Psychotherapy and Psychosomatics, 73, 107-116. 
Leverich, G. S., McElroy, S. L., Suppes, T., Keck, P. E., Jr., Denicoff, K. D., Nolen, W. A., et al. (2002). Early physical and sexual abuse associated with an adverse course of bipolar illness.

Biological Psychiatry, 51, 288-297.

Leverich, G. S., \& Post, R. M. (2006). Course of bipolar illness after history of childhood trauma. Lancet, 367, 1040-1042.

Lin, P. I., McInnis, M. G., Potash, J. B., Willour, V., MacKinnon, D. F., DePaulo, J. R., et al. (2006). Clinical correlates and familial aggregation of age at onset in bipolar disorder. American Journal of Psychiatry, 163, 240-246.

Maguire, C., McCusker, C. G., Meenagh, C., Mulholland, C., \& Shannon, C. (2008). Effects of trauma on bipolar disorder: the mediational role of interpersonal difficulties and alcohol dependence. Bipolar Disorders, 10, 293-302.

Meyer, I. H., Muenzenmaier, K., Cancienne, J., \& Struening, E. (1996). Reliability and validity of a measure of sexual and physical abuse histories among women with serious mental illness. Child Abuse \& Neglect, 20, 213-219.

Montgomery, S. A., \& Asberg, M. (1979). A new depression scale designed to be sensitive to change. British Journal of Psychiatry, 134, 382-389.

Moskvina, V., Farmer, A., Swainson, V., O'Leary, J., Gunasinghe, C., Owen, M., et al. (2007). Interrelationship of childhood trauma, neuroticism, and depressive phenotype. Depression and Anxiety, 24, 163-168.

Mueser, K. T., Bolton, E., Carty, P. C., Bradley, M. J., Ahlgren, K. F., Distaso, D. R., et al. (2007). The Trauma Recovery Group: a cognitive-behavioral program for post-traumatic stress disorder in persons with severe mental illness. Community Mental Health Journal, 43, 281-304. Myin-Germeys, I., Peeters, F., Havermans, R., Nicolson, N. A., DeVries, M. W., Delespaul, P., et al. (2003). Emotional reactivity to daily life stress in psychosis and affective disorder: an 
experience sampling study. Acta Psychiatrica Scandinavica, 107, 124-131.

Nemeroff, C. B. (2004). Neurobiological consequences of childhood trauma. The Journal of Clinical Psychiatry, 65 Suppl 1, 18-28.

Nurnberger, J. I., Jr., Blehar, M. C., Kaufmann, C. A., York-Cooler, C., Simpson, S. G., Harkavy-Friedman, J., et al. (1994). Diagnostic interview for genetic studies. Rationale, unique features, and training. NIMH Genetics Initiative. Archives of General Psychiatry, 51, 849-859. Ogilvie, A. D., Morant, N., \& Goodwin, G. M. (2005). The burden on informal caregivers of people with bipolar disorder. Bipolar Disorders, 7 Suppl 1, 25-32.

Otte, C., Neylan, T. C., Pole, N., Metzler, T., Best, S., Henn-Haase, C., et al. (2005). Association between childhood trauma and catecholamine response to psychological stress in police academy recruits. Biological Psychiatry, 57, 27-32.

Paivio, S. C., \& Cramer, K. M. (2004). Factor structure and reliability of the Childhood Trauma Questionnaire in a Canadian undergraduate student sample. Child Abuse \& Neglect, 28, 889-904. Paquette, D., Laporte, L., Bigras, M., \& Zoccolillo, M. (2004). Validation of the French version of the CTQ and prevalence of the history of maltreatment. Santé Mentale au Québec, 29, 201220.

Paykel, E. S. (2003). Life events and affective disorders. Acta Psychiatrica Scandinavica Supplementum, 418, 61-66.

Perlick, D., Clarkin, J. F., Sirey, J., Raue, P., Greenfield, S., Struening, E., et al. (1999). Burden experienced by care-givers of persons with bipolar affective disorder. British Journal of Psychiatry, 175, 56-62.

Post, R. M. (1992). Transduction of psychosocial stress into the neurobiology of recurrent affective disorder. American Journal of Psychiatry, 149, 999-1010.

Post, R. M., \& Leverich, G. S. (2006). The role of psychosocial stress in the onset and 
progression of bipolar disorder and its comorbidities: the need for earlier and alternative modes of therapeutic intervention. Development and Psychopathology, 18, 1181-1211.

Preisig, M., Fenton, B. T., Matthey, M. L., Berney, A., \& Ferrero, F. (1999). Diagnostic interview for genetic studies (DIGS): inter-rater and test-retest reliability of the French version. European Archives of Psychiatry and Clinical Neuroscience, 249, 174-179.

Price, J. L., Hilsenroth, M. J., Petretic-Jackson, P. A., \& Bonge, D. (2001). A review of individual psychotherapy outcomes for adult survivors of childhood sexual abuse. Clinical Psychology Review, 21, 1095-1121.

Putnam, F. W., \& Hulsmann, J. E. (2002). Pharmacotherapy for survivors of childhood trauma. Seminars in Clinical Neuropsychiatry, 7, 129-136.

Read, J., van Os, J., Morrison, A. P., \& Ross, C. A. (2005). Childhood trauma, psychosis and schizophrenia: a literature review with theoretical and clinical implications. Acta Psychiatrica Scandinavica, 112, 330-350.

Romero, S., Delbello, M. P., Soutullo, C. A., Stanford, K., \& Strakowski, S. M. (2005). Family environment in families with versus families without parental bipolar disorder: a preliminary comparison study. Bipolar Disorders, 7, 617-622.

Roy, A. (2002). Self-rated childhood emotional neglect and CSF monoamine indices in abstinent cocaine-abusing adults: possible implications for suicidal behavior. Psychiatry Research, 112, $69-75$.

Rush, A. J. (2003). Toward an understanding of bipolar disorder and its origin. Journal of Clinical Psychiatry, 64 Suppl 6, 4-8.

Shack, A. V., Averill, P. M., Kopecky, C., Krajewski, K., \& Gummattira, P. (2004). Prior history of physical and sexual abuse among the psychiatric inpatient population: a comparison of males and females. The Psychiatric Quartely, 75, 343-359. 
Smoller, J. W., \& Finn, C. T. (2003). Family, twin, and adoption studies of bipolar disorder. American Journal of Medical Genetics. Part C, Seminars in Medical Genetics, 123, 48-58.

Smoller, J. W., \& Gardner-Schuster, E. (2007). Genetics of bipolar disorder. Current Psychiatry Reports, 9, 504-511.

Spencer, T. J., Biederman, J., Wozniak, J., Faraone, S. V., Wilens, T. E., \& Mick, E. (2001). Parsing pediatric bipolar disorder from its associated comorbidity with the disruptive behavior disorders. Biological Psychiatry, 49, 1062-1070.

Todd, R. D., Geller, B., Neuman, R., Fox, L. W., \& Hickok, J. (1996). Increased prevalence of alcoholism in relatives of depressed and bipolar children. Journal of the American Academy of Child and Adolescent Psychiatry, 35, 716-724.

Wheeler, K. (2007). Psychotherapeutic strategies for healing trauma. Perspectives in Psychiatric Care, 43, 132-141. 
Table 1 : Demographic and clinical characteristics of bipolar patients $(n=206)$ and control subjects $(n=94)$

\begin{tabular}{lll}
\hline Group & Bipolar patients & Control subjects \\
\hline Sex ratio (men/women) * & $0.69(84 / 122)$ & $1.61(58 / 36)$ \\
Age at interview $M(S D)$ & $41.7(12.6)$ & $41.2(11.9)$ \\
Bipolar disorder type I & $75.2 \%$ & $0 \%$ \\
Age at onset $M(S D)$ & $23.9(9.3)$ & - \\
Duration of illness $M(S D)$ & $17.8(11.2)$ & - \\
Family history of bipolar disorder & $46.9 \%$ & $0 \%$ \\
Psychotic symptoms (lifetime presence) & $57.1 \%$ & $0 \%$ \\
Suicide attempt (lifetime presence) & $40 \%$ & $0 \%$ \\
Panic disorder (with or without agoraphobia) & $19.9 \%$ & $0 \%$ \\
Social phobia & $10.4 \%$ & $0 \%$ \\
Generalized anxiety disorder & $10.8 \%$ & $0 \%$ \\
Alcohol or cannabis abuse/dependence & $30.7 \%$ & $0 \%$ \\
\hline p < .0001 & & $0 \%$ \\
\end{tabular}

The presence of posttraumatic stress disorder is not available (absence of specific section in the French version of the DIGS) 
Table 2 : Comparison between bipolar patients $(n=206)$ and controls $(n=94)$ for the prevalence of each childhood trauma subtype categorized along a gradient of 4 severity levels

\begin{tabular}{lllllll}
\hline Trauma subtype & Group & None & Low & Moderate & Severe & $p_{\text {exact }}$ \\
\hline \multirow{2}{*}{ Emotional neglect } & Bipolar & $15.53 \%$ & $45.63 \%$ & $22.82 \%$ & $16.02 \%$ & .03 \\
& Controls & $23.40 \%$ & $54.26 \%$ & $14.89 \%$ & $7.45 \%$ & \\
& Bipolar & $50.97 \%$ & $24.27 \%$ & $9.71 \%$ & $15.05 \%$ & $3.10^{-5}$ \\
Emotional abuse & Controls & $76.60 \%$ & $18.09 \%$ & $3.19 \%$ & $2.12 \%$ & \\
& Bipolar & $72.81 \%$ & $17.48 \%$ & $5.34 \%$ & $4.37 \%$ & .01 \\
Physical neglect & Controls & $87.23 \%$ & $7.45 \%$ & $5.32 \%$ & $0.00 \%$ & .04 \\
& Bipolar & $77.67 \%$ & $12.14 \%$ & $5.34 \%$ & $4.85 \%$ & .10 \\
Physical abuse & Controls & $91.49 \%$ & $5.32 \%$ & $2.13 \%$ & $1.06 \%$ & \\
\hline & Bipolar & $68.93 \%$ & $11.17 \%$ & $9.71 \%$ & $10.19 \%$ & \\
\hline
\end{tabular}

Table 3 : Spearman correlations among the five trauma subtypes in the whole sample (pooling bipolar patients and controls, $N=300$ )

Trauma subtypes $\quad$ Emotional abuse $\quad$ Physical neglect Physical abuse Sexual abuse

\begin{tabular}{lcccc}
\hline Emotional neglect & $.51 * *$ & $.50 * *$ & $.31 * *$ & $.18 *$ \\
Emotional abuse & - & $.39 * *$ & $.53 *$ & $.38 * *$ \\
Physical neglect & - & - & $.30 * *$ & $.21 *$ \\
Physical abuse & - & - & - & $.44 * *$
\end{tabular}

$* * \mathrm{p}<.0001 ; * \mathrm{p}<.002$ 
Table 4: Results of logistic regressions testing for an association between disease status and the five trauma subtypes

\begin{tabular}{|c|c|c|c|c|c|c|c|c|c|c|c|}
\hline & \multicolumn{6}{|c|}{ Simple logistic regression } & \multicolumn{5}{|c|}{ Multiple logistic regression $(-2 \log \mathrm{L})=340.59$} \\
\hline & $B$ & $S E B$ & p value & $-2 \log L$ & Crude OR & $95 \% \mathrm{CI}$ & $B$ & $S E B$ & p value & Adjusted OR* & $95 \% \mathrm{CI}$ \\
\hline Emotional neglect & 0.44 & 0.15 & .003 & 362.04 & 1.56 & $1.16-2.08$ & 0.08 & 0.18 & .63 & 1.09 & $0.77-1.54$ \\
\hline Emotional abuse & 0.76 & 0.18 & $<.0001$ & 346.98 & 2.15 & $1.52-3.04$ & 0.63 & 0.21 & .003 & 1.88 & $1.23-2.86$ \\
\hline Physical neglect & 0.57 & 0.23 & .01 & 365.26 & 1.77 & $1.13-2.78$ & 0.25 & 0.25 & .32 & 1.28 & $0.79-2.10$ \\
\hline Physical abuse & 0.65 & 0.25 & .01 & 363.95 & 1.92 & $1.17-3.16$ & 0.02 & 0.31 & .95 & 1.02 & $0.56-1.88$ \\
\hline Sexual abuse & 0.39 & 0.16 & .01 & 362.88 & 1.47 & $1.09-2.00$ & 0.16 & 0.18 & .36 & 1.18 & $0.83-1.67$ \\
\hline
\end{tabular}

* Adjusted OR correspond to the stratified estimate of the odds ratio adjusted for the four other CTQ traumas. 
Figure 1 : Proportion of bipolar patients $(n=206)$ and controls $(n=94)$ for each emotional abuse severity level (none, low, moderate, severe) $305 \times 174 \mathrm{~mm}(96 \times 96$ DPI) 